\title{
Sequential polyandry affords post-mating sexual selection in the mouths of cichlid females
}

\author{
Simone Immler • Michael Taborsky
}

Received: 27 October 2008 /Revised: 24 February 2009 /Accepted: 24 February 2009/Published online: 14 March 2009

(C) Springer-Verlag 2009

\begin{abstract}
Females mating with multiple males may obtain direct benefits such as nuptial gifts or paternal care or indirect (i.e. genetic) benefits resulting in higher-quality offspring. While direct benefits are easily identified, it is difficult to determine indirect benefits, and it is hence largely unclear how they are obtained. This is particularly true in species with external fertilisation, where females seem to have little control over fertilisation. In cichlids, most maternal mouthbrooders show sequential multiple mating, where females visit several males for egg deposition. Genetic data revealed that multiple paternity of eggs and young in the mouth of females is common, but behavioural data of female spawning decisions are missing. Here, we test four hypotheses to explain female multiple mating in the maternally mouthbrooding cichlid, Ophthalmotilapia ventralis: (1) fertilisation insurance, (2) genetic bet-hedging, (3) female choice and (4) 'sperm shopping' (i.e. induction of sperm competition resulting in sexually selected sperm). Detailed observations of spawning behaviour in the field combined with histological analyses of the male reproductive organs suggest that fertilisation insurance, genetic bet-hedging and pre-mating female choice are
\end{abstract}

Communicated by K. Lindström

S. Immler $(\bowtie) \cdot$ M. Taborsky

Institute of Zoology, Div. Behavioural Ecology,

University of Bern,

Wohlenstrasse $50 \mathrm{~A}$,

3032 Hinterkappelen, Switzerland

e-mail: simone.immler@ebc.uu.se

Present address:

S. Immler

Evolutionary Biology Centre/Animal Ecology,

University of Uppsala,

Norbyvägen 18d,

75236 Uppsala, Sweden unlikely to explain the sequential female multiple mating in $O$. ventralis. Instead, cryptic female choice by sperm shopping, i.e. post-mating sexual selection, is most compatible with our data and might be the major ultimate cause of multiple mating in females of this species and of mouthbrooding cichlids with maternal care in general. Our study provides new insight into ultimate causes of sequential polyandry in species with external fertilisation, as hitherto post-mating sexual selection by cryptic female choice has been assumed to be incompatible with external fertilisation mechanisms except by components of the ovarian fluid.

Keywords Polyandry · External fertilisation - Sperm competition - Cryptic female choice - Ophthalmotilapia ventralis $\cdot$ Lake Tanganyika $\cdot$ Testis histology

\section{Introduction}

Multiple mating of females is widespread in animals (Gowaty 1994; Zeh and Zeh 2003; e.g. mammals: Gomendio and Roldan 1991; Stockley 2003; birds: Griffith et al. 2002; fish: Avise et al. 2002; Nordeide 2007; insects: Arnqvist and Nilsson 2000; Wiklund et al. 2001; Brown and Schmid- Hempel 2003; Torres-Vila et al. 2005), yet its functional significance is still poorly understood and highly debated (Hosken and Blanckenhorn 1999; Simmons 2001, 2003, 2005; Colegrave et al. 2002; Zeh and Zeh 2003). Females are thought to gain either (1) direct benefits such as nutrients (e.g. from nuptial gifts), fertility insurance or paternal investment (Birkhead et al. 1987; Simmons 1992; Sheldon 1994; Andersson 2005) or (2) indirect, that is, genetic benefits based on male quality (Kempenaers et al. 1992; Keller and Reeve 1995; Zeh and Zeh 1996; Yasui 
1998; Jennions and Petrie 2000; Tregenza and Wedell 2000; Colegrave et al. 2002; Ivy and Sakaluk 2005; Rudolfsen et al. 2005). Genetic benefits raise the fitness of a female's offspring, which is either achieved by chance when females use multiple partners without choosing among them (i.e. female bet-hedging to increase the genetic variance of their offspring; Yasui 2001) or by female preference for high-quality males. Traditionally, females have been thought to choose males by evaluating male traits and resources such as secondary sexual traits, body size, territory quality and social rank (Andersson 1994; Maynard-Smith and Harper 2003). However, there is also growing evidence for post-mating sexual selection where females appear to assess male quality by sperm quality (Eberhard 1996; Wirtz 1997; Stockley 1999; Birkhead and Pizzari 2002; Pizzari and Birkhead 2002). 'Sperm selection' is considered to be a possible way of cryptic female choice (Birkhead et al. 1993; Wirtz 1997), and there is empirical evidence that better sperm competitors sire higher-quality offspring (Konior et al. 2001; Hosken et al. 2003; Neff 2004; Fisher et al. 2006; Simmons and Kotiaho 2007). However, cryptic female choice by sperm selection so far has been studied mainly in species with internal fertilisation, as in external fertilisers female control over fertilisation is limited (Taborsky 1998; but see Urbach et al. 2005).

In fish with external fertilisation, polyandry is widespread and may be divided into 'passive' and 'active' polyandry. Passive polyandry occurs in species with group spawning or parasitic spawning, where females seem to have very limited influence on who is fathering their offspring (Taborsky 1994). In these mating systems, sperm competition may strongly influence the mating success of each participating male (Parker 1990a,b; Taborsky 1998, 2008; Vladic and Järvi 2001; Schulte-Hostedde and Burness 2005; Linhart et al. 2005). In contrast, in 'actively' polyandrous systems such as in many lekking species, females visit several males sequentially and hence have increased control over paternity. Sequential polyandry appears to be widespread in maternally mouthbrooding African cichlids (McKaye 1991; Höglund and Alatalo 1995; Kellogg et al. 1995; Kuwamura 1997; Schaedelin and Taborsky 2006), but its functional significance is poorly understood, mainly because detailed observations of spawning behaviour in nature are missing. Fertility insurance has been proposed to be a possible direct benefit of sequential multiple mating in external fertilisers (Barlow 2000). Furthermore, sequential multiple mating may provide indirect (i.e. genetic) benefits for females by assessing male quality either before or at mating (i.e. female choice) or thereafter (i.e. sexually selected sperm).

In species with sequential polyandry, post-mating sexual selection has received only limited attention, as the combination of sequential mating and external fertilisation seems to exclude the possibility of sperm competition and hence the hypothesis of sexually selected sperm (Keller and Reeve 1995; Hosken et al. 2003). Reasons for this assumption are (1) the separation in time between matings with different males and (2) limited sperm longevity in externally fertilising species (especially in fresh water; Billard 1978; Morisawa 1994; Takai and Morisawa 1995), which in combination both seem to exclude the encounter between active sperm of different males. However, preliminary behavioural observations of mouthbrooding cichlids suggest that sperm of different males might meet inside the female's mouth and compete amongst each other: In most mouthbrooding cichlids, eggs are picked up by the female immediately after deposition (Wickler 1962a, b), and fertilisation takes place in the female mouth (Mrowka 1987; Rossiter and Yamagashi 1997; Barlow 2000). Various mechanisms have evolved in different species to facilitate the sperm uptake into the female's mouth (Wickler 1962a, b; Mrowka 1987). In some species, females nibble directly at the male genital papilla, in others more complex mechanisms such as the use of 'egg dummies' located near the male genital papilla induce the female to snatch them, which results in sperm uptake (Wickler 1962a, b; Hert 1989). The limited sperm longevity in aquatic environments due to osmolality stress has been overcome by many fish species by enclosing sperm in a mucous substance to protect them, and such sperm are able to fertilise eggs for hours (Trippel and Morgan 1994; Marconato et al. 1996; Scaggiante et al. 1999; Rasotto and Mazzoldi 2002; Elofsson et al. 2003). A similar substance has been found in the gonads of the mouthbrooding cichlid Oreochromis aureus (Grier and Fishelson 1995).

Here, we study female multiple sequential mating in an externally fertilising teleost to understand why females mate with multiple males. We recorded the spawning behaviour of the maternal mouthbrooder Ophthalmotilapia ventralis in the field and analysed the data with respect to four non-exclusive, alternative hypotheses to explain this mating pattern: (1) fertilisation insurance, (2) bet-hedging, (3) female choice by pre-mating sexual selection and (4) cryptic female choice by post-mating sexual selection ('sperm shopping'). In addition, we measured the gonadosomatic index and used histological analyses of testes to check for indications of sperm competition, mechanisms of sperm release and ejaculate characteristics.

\section{Material and methods}

Study species and spawning behaviour

O. ventralis (Ectodini; Cichlidae) is an endemic cichlid of Lake Tanganyika in which lekking males build bowers of 
fine sand and algae debris on boulders, which are visited by females for spawning. Territorial males are larger in body size (mean standard length, SL: head to beginning of tail fin, $8.15 \mathrm{~cm} \pm 0.25 \mathrm{SD}$ ) than females (SL, $7.33 \mathrm{~cm} \pm$ $0.47 \mathrm{SD}$ ) and have elongated pelvic fins (mean length, $5.6 \mathrm{~cm} \pm 0.4 \mathrm{SD}$ ) with bright yellow tips (Pellegrin 1904; Liem 1981). Territorial males show a flashing whitish nuptial colouration, which makes them visible over large distances. The cryptically coloured females live in loose shoals, which they leave for spawning.

The spawning behaviour of $O$. ventralis is very characteristic and involves three main steps: (1) Females ready to spawn have an extended abdomen and when they approach a lek they are courted by males that try to lead them to their bower by lateral display and exaggerated lead swimming. (2) The female may follow the male onto his bower (hereafter referred to as a 'visit'), and 'spawning bouts' will ensue: The male places his genital papilla onto the bower and quivers (probably the moment of sperm release; Fig. 1a). Then, he raises some centimetres from the bower and stretches his elongated pelvic fins maximally from the body, so that their brightly coloured tips are placed approximately where he had just released sperm. This stimulates the female to approach and snatch at the gaudy fin tips (likely to be the moment of uptake of the deposited sperm; Fig. 1b). Thereafter, the male leaves the bower, whereas the female stays and starts circling on the bower, where she may lay up to three eggs in successive turns, which she takes up quickly (Fig. 1c). (3) After the spawning bout, the female leaves the bower, and the male resumes lateral displays and lead swimming to bring the female back to the bower for another spawning bout. Females often switch between males for subsequent spawning bouts and usually visit several males for the deposition of a whole clutch (hereafter referred to as 'spawning event'). Females visit different males during all stages of a spawning event (1) before starting to lay eggs, (2) during egg laying and (3) after the last egg has been laid.

Hypotheses accounting for sequential polyandry

To explain multiple mating of $O$. ventralis females, we tested predictions derived from four mutually nonexclusive, alternative hypotheses.

\section{Fertilisation insurance hypothesis}

The number of sperm released by one male is not sufficient to ensure the fertilisation of an entire clutch of eggs (Birkhead et al. 1987), and hence, females are forced to visit several males to get all eggs fertilised. One possible
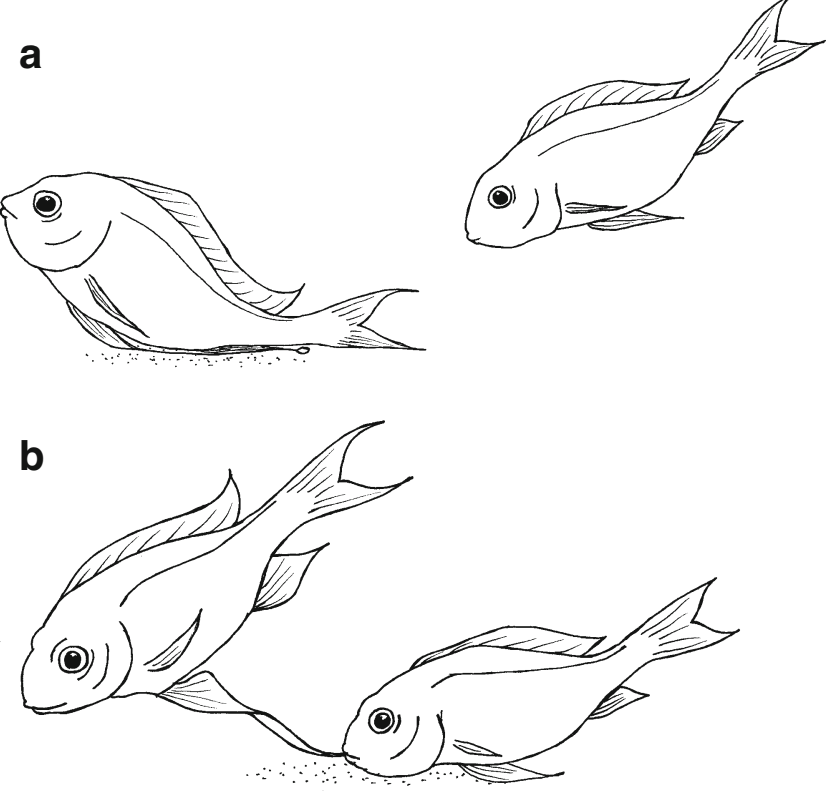

C

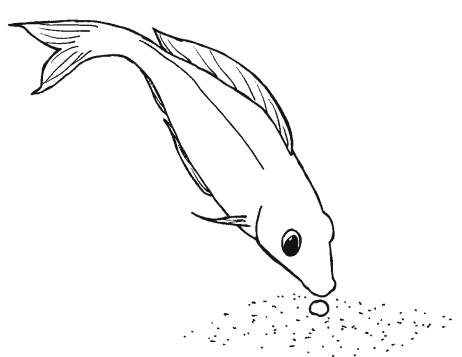

Fig. 1 Spawning bout: a The male presses his genital papilla against the substrate and quivers (probably moment of sperm release); $\mathbf{b}$ the male raises some centimetres from the bower and stretches his elongated pelvic fins maximally from the body to display their brightly coloured tips, which are snatched by the female (likely to be the moment of uptake of the deposited sperm); $\mathbf{c}$ the male leaves the bower, and the female stays and starts circling on the bower and may lay up to three eggs, which she picks up (drawings by S. Immler)

reason for sperm limitation might be sperm depletion of males due to repeated mating (Nakatsuru and Kramer 1982; Warner 1997; Wedell et al. 2002). This hypothesis predicts (1) a positive correlation between the total number of eggs laid and the number of separate spawning bouts induced by a female during a spawning event at a particular bower, as more eggs need more sperm to be fertilised and (2) the probability of sperm depletion of male $O$. ventralis due to frequent ejaculations is high.

\section{Genetic bet-hedging hypothesis}

Females mate with many different males to increase the genetic diversity of their offspring (Yasui 2001; Fox and Rauter 2003). It is difficult to predict specific mating patterns according to this hypothesis. However, females laying larger clutches may be expected to visit more 
different males than females with smaller clutches to make use of their potential to increase genetic diversity of their offspring. We would therefore expect that the number of different males selected for spawning should rise with an increasing number of eggs laid per clutch in order to increase the genetic diversity of offspring.

\section{Female choice hypothesis}

Females choose males by assessing their genetic quality in relation to correlating traits such as body size, body colouration or territory size (Andersson 1994). In this case, females may be expected (a) to continue their search for higherquality males after they started to spawn, (b) to inspect several males without actual spawning and (c) to return to specific males. In addition, we would expect females to stop or reduce seeking for more males over time since the probability to find a better male decreases with time (Dombrovsky and Perrin 1994; Collins et al. 2006). Predictions from this hypothesis are (1) a positive correlation between both, male quality traits such as body size, and spawning site quality (e.g. bower size, area and height of defended boulder) with mating success; (2) that females pay short visits without spawning bout to males which they visit again later for egg laying to assess male quality; (3) a declining number of different visited males during the course of egg laying as the chance of encountering higher-quality males decreases over time; (4) females visit different males before and during egg laying, but not after egg laying has stopped.

\section{Sexually selected sperm hypothesis (sperm shopping)}

There may be positive genetic associations between a male's sperm competitiveness and the general viability of his offspring ('good sperm' models; Yasui 1997; Fisher et al. 2006) or multiply mating females produce sons that will be successful in sperm competition and daughters that will induce sperm competition through multiple mating ('sexy sperm' models; Harvey and May 1989; Keller and Reeve 1995). If such a sexually selected sperm process occurs, females would incite sperm competition by switching between males to collect their sperm without much delay. This hypothesis predicts (1) a short time interval between subsequent spawning bouts with different males; (2) initiation of ejaculation and sperm collection from different males after short delays only, e.g. without spawning additional eggs with the previous male in between, to maximise the sperm competition potential; (3) performance of spawning bouts also without egg laying and female visits of males even after egg laying has ceased as during this phase females may still carry unfertilised eggs in their mouth if eggs are not immediately fertilised at deposition (Mrowka 1987); (4) shorter time intervals between egg deposition and the subsequent spawning bout if the latter is performed with a different male than with the same male to increase the chance of sperm competition; (5) a mechanism prolonging sperm longevity in water.

\section{Sexual conflict}

We tested for a possible conflict of interest between the sexes caused by pre-oviposition ejaculation as the male has limited information about the female's egg allocation. Sperm are costly (Nakatsuru and Kramer 1982; Wedell et al. 2002), and therefore, males are expected to reduce costs by optimising ejaculate expenditure. They should be able to decide about sperm and ejaculate allocation dependent on whether a visiting female is able to lay eggs or carries fertilisable eggs in her mouth. We therefore compare (1) the number of spawning bouts performed by males with full information about a female's spawning condition, i.e. after the female has laid an egg with this male, with (2) the number of spawning bouts performed when no eggs can be fertilised (i.e. no eggs are laid or carried); and we estimate (3) the proportion of males performing spawning bouts without any chance to fertilise eggs.

\section{Behavioural observations}

We marked 52 male territories with numbered stones during March and April 2001 at Kasakalawe point near Mpulungu, Zambia, at the southern end of Lake Tanganyika ( $8^{\circ} 46.849^{\prime} \mathrm{S}$, $\left.31^{\circ} 04.882^{\prime} \mathrm{E}\right)$. We measured the distances between the centres of bowers of neighbouring males with a tape measure and determined maximum length, maximum width and maximum height of 44 boulders with bowers. In addition, we measured the diameter of 39 bowers with a ruler, which is straightforward because the bowers are usually perfectly round. Territory owners were observed for spawning activity for $5 \mathrm{~min} /$ day at different times during daylight hours, and the numbers of visiting and egg laying females were recorded. Independently, 67 females ready to spawn (round belly and empty buccal cavity) were detected and followed for continuous focal animal watches. Time was recorded continuously from the moment of the first visit of a male until the female left the last male she visited. The observation of a female was ended after a female had not visited any male for $15 \mathrm{~min}$. We divided a spawning event into three phases: (1) The pre-egg laying phase lasted from a female's first visit of a male's bower until the visit during which the first egg was laid; (2) the egg laying phase extended from the first to the last visit during which an egg was laid; and (3) the phase after egg laying had stopped lasted from the last visit in which an egg was laid until the female left the last male she visited. Of each bower visit we recorded (a) arrival and departure time of the female on the bower, (b) time of each spawning bout and (c) 
time of each egg deposition; we counted (d) the number of visits, (e) the number of short visits (visits without spawning bout), (f) the number of spawning bouts performed, (g) the number of different males visited and $(h)$ the number of eggs laid with each male.

We tested the data for deviation from normal distribution using Shapiro-Wilk's tests. To test for correlations, we used Spearman rank correlation analyses, and to test for correlations across females, we performed a derived variable analysis using Spearman's rho in a one-sample $t$ test against zero. To compare data between different phases, we used paired $t$ tests for normally distributed data and Wilcoxon matched-pairs signed-ranks tests for other data. Statistical analyses were performed using SPSS version 12.0.

Testis size, histology and histochemistry

Fifteen male $O$. ventralis were collected in the field at the end of the observation period, i.e. after they had been observed on their bowers for at least 3 weeks. Individual males were identified by their specific dark markings on the flanks, which is very easy and reliable in this species. They were killed with a lethal dose of anaesthetic (MS222, Sandoz) and measured for standard length (SL), maximum body height and maximum belly width, and they were weighed for body weight (WT).

The entire reproductive tract was removed, weighed to the nearest $\mathrm{mg}$ and fixed for a minimum of 6 days in Dietrich's solution (900 $\mathrm{ml}$ distilled water, $450 \mathrm{ml} 95 \%$ ethanol, $150 \mathrm{ml} \mathrm{40 \%}$ formaldehyde, $30 \mathrm{ml}$ acetic acid). Then, it was dehydrated in ethanol, embedded in paraplast and sectioned serially at $6-7 \mu \mathrm{m}$. Sections from each specimen were stained with haematoxylin and eosin. For polysaccharide detection, sections were stained using the reaction of periodic acid-Schiff (PAS; Pearse 1985). Alcian Blue staining at $\mathrm{pH} 1.0$ and 2.5 was performed to detect sulphated and non-sulphated mucins (Pearse 1985).

\section{Results}

Male and bower measures

Mean SL of collected territorial males was $8.05 \mathrm{~cm} \pm$ $0.24 \mathrm{SD}$, which was strongly correlated with body weight (13.3 $\mathrm{g} \pm 1.68 ; N=15 ; r=0.85, P<0.001)$ and mean maximum body height $(2.87 \mathrm{~cm} \pm 0.12 ; r=0.63, P=0.009)$, whereas there was no significant correlation between SL and mean maximum belly width $(1.14 \mathrm{~cm} \pm 0.09, r=0.25$, $P=0.36)$. Bower rocks were on average $27.3 \mathrm{~cm}$ long $( \pm 7.5$; $N=44), 20.8 \mathrm{~cm}$ wide $( \pm 3.6$; surface area $582.5 \mathrm{~cm} 2 \pm$ $245.4)$ and $13.2 \mathrm{~cm}( \pm 3.5) \mathrm{high}$, and the mean distance between neighbouring bowers was $2.73 \mathrm{~m}( \pm 1.6$, $\mathrm{min}=$ $0.5 \mathrm{~m}, \max =10 \mathrm{~m} ; N=66$ nearest neighbour measures). Bowers had a mean diameter of $11.56 \mathrm{~cm} \pm 1.64 \mathrm{SD}(N=$ 39).

Spawning observations

During 92.75 observation hours of 52 different territorial males, we counted a total of 67 spawnings (defined as observation of a female visiting a bower, with or without egg deposition), during which we observed the laying of a total of 57 eggs. We observed nine complete spawning events (i.e. laying of all eggs of a clutch), in six of which all individual males participating could be identified. In the remaining three spawning events, females left the marked area during spawning, and male identification was impossible as the visited males had not been registered beforehand. A complete spawning event lasted on average $35.5 \mathrm{~min}$ ( $\pm 9.2 \mathrm{SD}$; range 22.5-50.3). Females switched between eight different males on average (range 4 to 15 ) in 19.6 visits $( \pm 11.3)$ and laid eggs with 2.5 different males (range one to six). On average, a female laid 13.2 eggs per clutch $( \pm 3.7)$.

\section{Fertilisation insurance hypothesis}

(1) There was no correlation between the total number of spawning bouts and the total number of eggs laid during one visit at a particular bower (Spearman, $r_{\mathrm{S}}=-0.14, P=0.72, N=$ 9). (2) The mean number of spawning bouts performed by an individual male during one spawning event of one female was $6.5 \pm 5.3 \mathrm{SD} ;(N=6)$. We also estimated the maximum number of spawning bouts performed by one male during a spawning event. We did this in four steps: (a) In each completely observed spawning event, we identified the male which performed most spawning bouts with that particular female. (b) From these six identified males (in six complete spawning events, all males could be identified, see above), we calculated the number of spawning bouts performed, which was $16.5 \pm 8.0 \mathrm{SD}(N=6)$. (c) Furthermore, from our general observations of the lek, we estimated that each male was involved in two spawning events per day. (d) If the most successful males performed 16.5 spawning bouts per spawning event and two spawning events per day, this results in a maximum of 37 spawning bouts per male and day.

\section{Genetic bet-hedging hypothesis}

There was no significant correlation between the number of eggs laid and the number of visited males (males visited before egg laying had started were excluded; $r_{\mathrm{S}}=-0.66, P=$ $0.15, N=6$; note that the relationship is negative, which is opposite to the prediction. The lack of significance may be due to small sample size). 


\section{Female choice hypothesis}

(1) No significant correlation existed between any of the male and territory traits measured and the number of female visits per male (SL: $r_{\mathrm{S}}=-0.11, P=0.69, N=15$; pelvic fin length: $r_{\mathrm{S}}=0.14, P=0.61, N=15$; rock surface area: $r_{\mathrm{S}}=$ $-0.13, P=0.4, N=44$; bower height: $r_{\mathrm{S}}=-0.24, P=0.12, N=$ 44; bower diameter: $r_{\mathrm{S}}=0.022, P=0.9, N=39$ ); (2) $19.3 \%$ of all males were visited by a short visit only, and $22.2 \%$ of all males were visited by a short visit before the respective females returned to them later to induce spawning bouts. (3) The number of different males visited did not differ between the different phases (before egg laying, 2.5 males \pm 1.1 SD; during egg laying, 3.2 males $\pm 2.6 \mathrm{SD}$; after egg laying, 3.7 males $\pm 1.4 \mathrm{SD}, N=6$ complete spawning events; Wilcoxon signed-ranks test: before vs during, $\mathrm{Z}=0.27, P=$
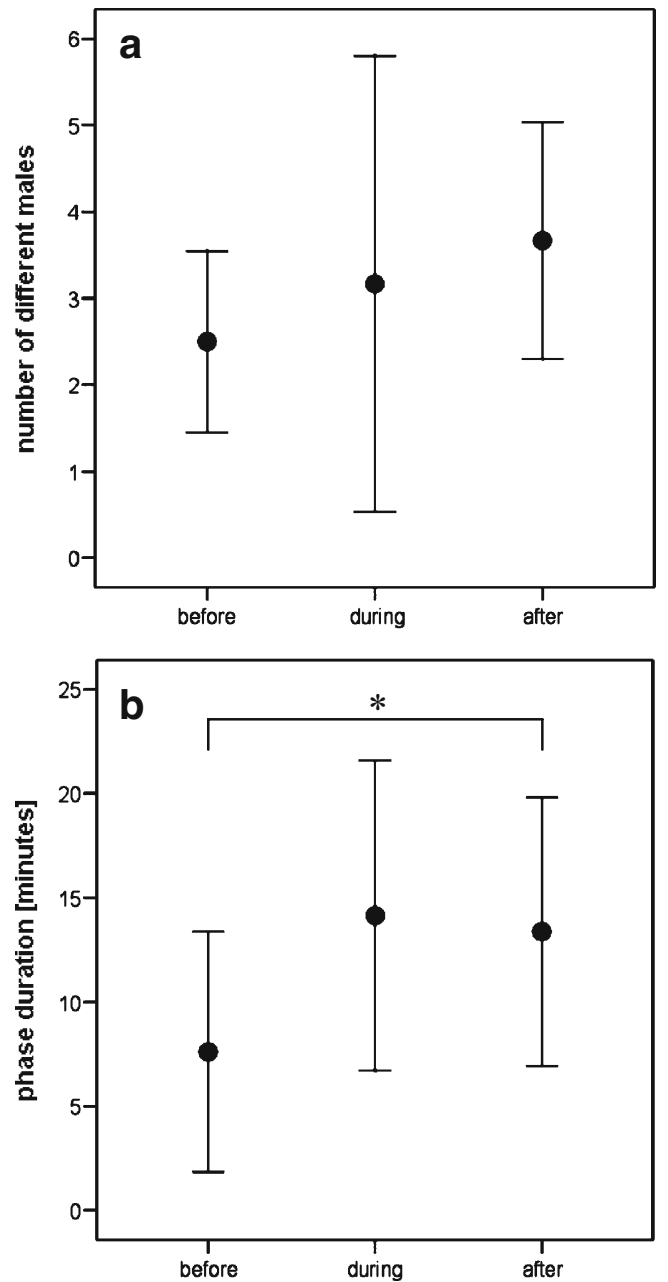

Fig. 2 a The number of different males visited during the three phases (before, during and after egg laying) of a spawning event (mean $\pm \mathrm{SD}, N=6$ ). b The durations of the phase before egg laying had started, the laying phase and the phase after egg laying had stopped (mean $\pm \mathrm{SD}, N=8$ ). Significant differences between phases are indicated by an asterisk $(p<0.01)$
0.79 ; before vs after, $\mathrm{Z}=1.16, P=0.25$; during vs after, $\mathrm{Z}=$ $0.64, P=0.52$; Fig. 2a). Although the difference between before and after egg laying is not significant probably due to low sample size, the effect size for the difference is about $1 \mathrm{SD}$, which is remarkable. (4) The phase after egg laying had stopped (983.13 $\mathrm{s} \pm 388.65 \mathrm{SD}, N=9)$ was significantly longer than the pre-laying phase (524.0 $\mathrm{s} \pm 368.68 ; N=9$; paired $t$ test, $t_{8}=-3.82, P=0.007$; Fig. $2 \mathrm{~b}$ ).

\section{Sexually selected sperm hypothesis (sperm shopping)}

(1) The mean time between the last spawning bout in a visit and the first spawning bout with a new male was $126.07 \mathrm{~s}$ $( \pm 87.2 \mathrm{SD} ; N=12)$. (2) In $65.9 \%$ of visits with egg deposition ( $N=41$ visits), the female induced one to three spawning bouts of the bower owner after the last egg of her visit was laid and before she switched to a new male. (3) All observed females continued inducing spawning bouts with different males after the last egg had been laid. In addition, the phase after egg laying was significantly longer than the phase before egg laying (see results reported above, "Female choice hypothesis", (4) of the "Results" section; Fig. 2b). (4) Time intervals between the last egg laid in a visit and the subsequent spawning bout induced with the same male in a next visit after having left the nest (40.1 $\mathrm{s} \pm 40.5 \mathrm{SD}, N=7$ ) did not differ significantly from the time intervals between egg laying and the subsequent spawning bout induced with a different male (76.6 $\mathrm{s} \pm$ 48.5 SD, $N=6$; $t$ test, $t_{11}=1.46, P=0.18$ ). (5) Males produce a mucous substance, which is likely to protect sperm against osmolality stress (see results of "Testis size, histology and histochemistry", below).

\section{Sexual conflict}

(1) In $16 \%$ of all spawning bouts, males could be certain about the presence of eggs since they witnessed egg laying in their own bower before they performed a spawning bout with the same female. To be conservative in these estimates, we assumed that males cannot identify individual females, and therefore, returning females were considered to be 'new' to the male. (2) In $55.2 \%$ of all male visits, the female carried eggs that had been laid earlier, in her buccal cavity; $23.7 \%$ of all spawning bouts were performed without any eggs laid or present in the female's buccal cavity; (3) $10.4 \%$ of all males performed spawning bouts with a female without any fertilisable eggs present and without being visited by the same female again later. (4) The time measured between sperm release and egg deposition within a spawning bout was $24.7 \mathrm{~s}( \pm 23.0 \mathrm{SD} ; N=12$ time intervals between sperm release and egg deposition). The time between the last egg laid in one visit and the first spawning bout with a different male was $177.9 \mathrm{~s}( \pm 124.4 \mathrm{SD}, N=12)$. 
Testis size, histology and histochemistry

Testes had a mean length of $2.36 \mathrm{~cm} \pm 0.28 \mathrm{SD}$ and a mean weight of $0.103 \mathrm{~g} \pm 0.027 \mathrm{SD}$. We calculated a mean GSI (=gonad weight/body weight $\times 100$ ) of $0.779 \pm 0.186$ SD. Testes are elongated, paired and rounded tubes suspended from the dorsal wall of the coelomic cavity by a short mesorchium. Gonoducts are present as two main testicular ducts (Grier 1981) running along the testis length, fusing in a common sperm duct shortly before reaching the urogenital opening.

Testes are organised in lobules, which are separated from each other by a thin layer of fibrous connective tissue. Lobules open into a main testicular duct, located ventromedially, on the testis side facing the dorsal mesentery. The lobule walls are lined with a germinal epithelium. Leydig cells build interstitial compact groups between the lobules throughout the whole length of the testes. The germinal epithelium shows spermatogonia distributed along its length and, consequently, can be defined as an unrestricted spermatogonial type, following Grier (1981). Spermatogenesis was fully active as all stages from spermatogonia to spermatids were observed, and all males showed mature sperm in their gonads. The main testicular ducts running along each testis are multi-chambered, and the chamber walls comprise a layer of connective tissue, a single-layered columnar epithelium, and they are rich in smooth muscle cells. The inner epithelium of the chamber walls and the testicular duct consists of columnar cells, of which the appical part reacted positively to PAS and to Alcian Blue at $\mathrm{pH} 1$ and 2.5. The sperm duct, arising from the fusion of the two main testicular ducts, has a similar structure. A homogeneous material staining for sialomucins was present in the chamber lumina in the testes mixed with sperm (M.P. Häsler, S. Immler \& M. Taborsky, unpubl. data).

\section{Discussion}

Sequential multiple mating in the maternally mouthbrooding cichlid $O$. ventralis appears to be driven primarily by postmating sexual selection. Our data suggest that direct benefits in the form of fertilisation insurance are unlikely to explain female spawning behaviour in this species. Furthermore, we found no evidence that females adopt a bet-hedging strategy to improve the fitness of their offspring or that they choose mating partners according to the quality of males or the spawning sites they provide. Below, we discuss our results in relation to each of the four hypotheses we considered.

Fertilisation insurance hypothesis

Fertilisation insurance is an unlikely explanation for polyandry in $O$. ventralis because: (1) Sperm depletion is unlikely to occur in male $O$. ventralis as the spawning frequency and the number of spawning bouts are relatively low (a maximum estimate of 37 ejaculations per male and day) in comparison to other cichlids (e.g. Lamprologus callipterus; Sato et al. 2004). All dissected males showed a high sperm content in their gonads with chambers filled with sperm. We found muscles around the testicular duct that could allow males to adjust ejaculate size. This mechanism is known from the blue-headed wrasse (Thalassoma bifasciatum), where dominant males may adjust ejaculate size to mating frequency and the intensity of sperm competition (Shapiro et al. 1994; Warner et al. 1995; Rasotto and Shapiro 1998). (2) Female O. ventralis produce small clutches compared to other fish species (Stockley et al. 1996), which should require a comparatively small number of sperm for fertilisation. We found no correlation between the number of eggs per clutch and the respective number of spawning bouts, i.e. females did not request more sperm when laying more eggs to guarantee fertilisation. (3) The site of fertilisation (i.e. the female buccal cavity) makes large numbers of sperm redundant, which contrasts with species where fertilisation occurs in the water column or on the substrate. In fact, a comparative study of Lake Tanganyika cichlids showed that substrate brooders have relatively larger testes (and probably much more sperm) than mouthbrooders (Balshine et al. 2001). Furthermore, in a mouthbrooding tilapia, for instance, densely packed sperm drops are directly taken up by spawning females, which creates high sperm concentrations in their buccal cavity (Wickler 1962a). Although we did not determine sperm packaging in $O$. ventralis, the mucous we found in the testicular duct might serve a similar function (Grier and Fishelson 1995).

Genetic bet-hedging hypothesis

Bet-hedging may be advantageous especially in small populations and unstable environments, where females may raise offspring fitness by mating with different males to increase the genetic diversity of their offspring (Yasui 2001). The ecology of $O$. ventralis makes bet-hedging an unlikely explanation for sequential polyandry because (a) the sublittoral zone of Lake Tanganyika is a remarkably stable environment (Coulter 1991) where large genetic variation among a female's offspring is unlikely to yield great fitness advantages, and (b) $O$. ventralis is a common species in the lake, and hence, population size is large (Konings 1988). Furthermore, we expected that if bethedging is important, females laying larger clutches should visit more different males to make use of their potential to increase genetic diversity among offspring. However, there was no positive but a negative correlation between the number of eggs laid and the number of visited males, albeit statistically non-significant. Together, these observations 
suggest that females do not adopt a bet-hedging strategy by spawning with many males randomly.

Female choice hypothesis

We found no evidence that pre-mating female choice is the major reason for female multiple mating in $O$. ventralis. Females visit different males before egg laying but return only rarely for egg deposition, and they spend almost twice as much time visiting different males after they have stopped to lay eggs than before laying has started. Furthermore, we found no correlation between the quality of males and their spawning sites (bowers and bower locations) with female preference, even though the traits measured included the clearest secondary sexual characters of this species. In the closely related Cyatopharynx furcifer, crater size and male building activity are apparently used by females as indicators of male quality (Schaedelin and Taborsky 2006). Other factors such as the bower position on the lek might be important for mate choice (Alatalo et al. 1991; Rintamäki et al. 1995). However, in O. ventralis, positions of bowers within the lek seem to be fixed, and males take over territories from previous owners. The 15 males we removed from their territory for the histological analyses were often immediately replaced by new males, and by the following day, all bowers were occupied by new owners. A possible criterion for female choice that we have not tested is that males might release pheromones during ejaculation, which might allow females to assess male quality (see also Plenderleith et al. 2005). The presence of Leydig cells in the testes could indicate the production of pheromones (M.P. Häsler, S. Immler \& M. Taborsky, unpubl. results), which may play an important role in male reproduction as shown in the black goby, Gobius niger (Colombo et al. 1980; Locatello et al. 2002; Immler et al. 2004).

Sexually selected sperm hypothesis

Our results support the hypothesis that post-mating sexual selection may be primarily responsible for multiple mating of female $O$. ventralis. The long phase after egg laying has stopped during which females continue visiting males and collecting sperm is the strongest support of the sexually selected sperm hypothesis. In addition, the frequent switch between males and the short intervals between subsequent visits with apparent uptake of sperm from different males suggest a high potential for sperm competition. The induced spawning bouts after laying eggs at a bower and immediately before switching to a new male increase the chance that active sperm of different males meet and compete. Besides serving the function of dense sperm packaging (see above), the mucous found in the testicular duct of $O$. ventralis is also suited to increase sperm longevity and to prolong sperm competitiveness. In two marine goby species, sperm packed in mucous similar to $O$. ventralis survive and fertilise eggs even for hours (Scaggiante et al. 1999). In O. ventralis, stripped sperm were found to be viable on a microscope slide in excess of 15 min (Haesler 2007). Sperm of different males are therefore likely to compete for fertilisation in the female buccal cavity, despite the fact that the interval between two subsequent ejaculations of different males may last up to 8 min. Furthermore, females often switch to and fro between two males, laying only a small number of eggs at a time for each male. For all these reasons, the sexually selected sperm hypothesis seems to be the most likely explanation for female multiple mating in $O$. ventralis. This was also corroborated by a paternity study showing that $83 \%$ of the clutches studied were sired by two or more males (Haesler 2007). Notably, males indeed sired offspring when a female did not lay eggs at their bowers but only collected their sperm; the longest interval between egg laying and sperm uptake resulting in successful fertilisation was 8 min (Haesler 2007).

There is empirical evidence from other species that sperm competition may influence the quality of resulting offspring. In bluegill sunfish, Lepomis macrochirus, parasitic males produce better sperm (Burness et al. 2004) and sire fitter offspring (Neff 2004). In the yellow dungfly, Scatophaga stercoraria, males that outcompete rivals in sperm competition sire higher-quality offspring (Hosken et al. 2003). Similarly, in the Trinidadian guppy, Poecilia reticulata, multiply mated females sired higher-quality offspring, suggesting that fitter males outcompete lower quality males in sperm competition (Evans and Magurran 2000). In addition, quantitative genetic data obtained from the dung beetle Onthophagus taurus support the role of a sexually selected sperm process in the evolutionary divergence of sperm (Simmons and Kotiaho 2007).

\section{Alternative explanations}

Which alternative mechanisms might be responsible for the reproductive pattern we found in this study? In particular, the post-spawning sperm collection of females at different males deserves to be scrutinised, as it is this trait that most clearly points towards the sexually selected sperm hypothesis. It is possible that females cannot determine in time that they have no further eggs ready to be laid. Such constraint might exist if their spawning behaviour is triggered by hormones, without any feedback from the content of the ovary. However, in the cichlid Astatotilapia burtoni, it has been shown that the gravidity state of females has a major impact on the hormones and hence the reproductive behaviour of females (Clement et al. 2005). In 
addition, the bower visits involve costs of time, energy and risk to the female and her offspring, which is important especially during brood care and should hence be selected against if they lack a function. Another possibility is that females are collecting sperm of different males for nutrition, which might be important particularly at the beginning of a long period of fasting caused by their mouthbrooding. However, this seems unlikely because sperm is poor in nutrition, and benefits for the female through sperm consumption seem too small to justify the additional visits. One could argue that females go for the accessory mucous produced by the testes, but this only shifts the question by one level: Why should males be selected to produce such substances if it is not for the protection of sperm, but only for the nutrition of females they have not even spawned with? We think, therefore, that the post-mating sexual selection hypothesis is the most parsimonious and hence most likely explanation for multiple sequential mating and sperm collection in this species, particularly during the post-laying period.

\section{Sexual conflict}

Pre-oviposition sperm release has been suggested to increase fertilisation success in three-spined sticklebacks (Le Comber et al. 2004). In O. ventralis, it may lead to a conflict of interest between the two sexes. For most spawning bouts, males lack information about whether a female carries fertilisable eggs or will lay eggs on their bower. Therefore, to maximise the chances to sire offspring, they must release sperm in every spawning bout before the female is laying. This is wasteful because half of all female visits and a quarter of all spawning bouts are performed without presence of fertilisable eggs. Sperm production is costly, and therefore, males are selected to optimise the number of sperm released (Nakatsuru and Kramer 1982; Wedell et al. 2002). The muscles surrounding the testicular duct are one way to do so. Males might use possible indicators such as a full, round belly of females (i.e. with eggs to be laid), a full buccal cavity (i.e. a female has laid many eggs already) or chemical cues to decide how much sperm to release. However, females seem to be largely in control over fertilisation in this species and probably in many other mouthbrooders with similar spawning habits (see Kuwamura 1997; Barlow 2000).

\section{Conclusions}

When interested in evolutionary mechanisms underlying multiple mating of females in the absence of paternal care, sequential polyandry in mouthbrooders is a suitable study system to evaluate alternative hypotheses. Nevertheless, to our knowledge, this is the first detailed quantitative study of mating behaviour of a lekking mouthbrooder in the field. Our data suggest that the fertilisation insurance and genetic bet-hedging hypotheses are unlikely explanations for female polyandry in this species. Regarding female choice for male quality, the mere existence of secondary sexual characters in males, such as elongated pelvic fins with bright yellow tips (Konings 1988, Salzburger et al. 2007), might indicate that female choice at the pre-mating stage does exist, which has been confirmed by an experimental laboratory study (Haesler 2007). The female choice hypothesis and the sexually selected sperm hypothesis assume female choice and sexual selection to take effect at different stages of the spawning event, which selects for very different traits. Our results suggest that inducement of sperm competition in the buccal cavity of females is an important mechanism responsible for multiple mating in female $O$. ventralis, which is particularly demonstrated by the long post-laying phase during, which females collect sperm from different males without laying eggs on their bowers.

Among mouthbrooders, multiple mating is exclusively found in species with maternal care, where males do not invest in the offspring. In contrast, biparental and paternal mouthbrooders are monogamous at least for the fertilisation of one clutch (Kuwamura 1997; Goodwin et al. 1998; Neat and Balshine-Earn 1999; Okuda 1999). Due to the fact that females are largely in control of fertilisations in maternal mouthbrooders, multiple mating may have evolved to increase offspring quality. From genetic data, this seems to be widespread (Kellogg et al. 1995; Parker and Kornfield 1996; Knight et al. 1998; Maan et al. 2004).

Acknowledgements We thank Mariella Rasotto for help with histological analyses and the Fisheries Department in Mpulungu, Zambia, for their technical support. We also thank two anonymous referees for helpful comments on an earlier version of the manuscript. This project was funded by the Swiss National Science Foundation (grants 3100-064396 and 3100A0-105626 to M.T.).

\section{References}

Alatalo R, Höglund J, Lundberg A (1991) Lekking in the black grouse- - a test of male viability. Nature 352:155-156

Andersson M (1994) Sexual selection. Princeton University Press, Princeton

Andersson M (2005) Evolution of classical polyandry: three steps to female emancipation. Ethology 111:1-23

Arnqvist G, Nilsson T (2000) The evolution of polyandry: multiple mating and female fitness in insects. Anim Behav 60:145-164

Avise JC, Jones AG, Walker D, DeWoody JA (2002) Genetic mating systems and reproductive natural histories of fishes: lessons for ecology and evolution. Annu Rev Genet 36:19-45

Balshine S, Leach BJ, Neat F, Werner NY, Montgomerie R (2001) Sperm size of African cichlids in relation to sperm competition. Behav Ecol 12:726-731 
Barlow GW (2000) How gametes meet. In: Barlow GW (ed) The cichlid fishes. Persus, Cambridge, pp 153-172

Billard R (1978) Changes in structure and fertilizing ability of marine and freshwater fish spermatozoa diluted in media of various salinities. Aquaculture 14:187-198

Birkhead TR, Pizzari T (2002) Postcopulatory sexual selection. Nature Reviews 3:262-273

Birkhead TR, Atkin L, Møller AP (1987) Copulation behaviour of birds. Behaviour 101:101-138

Birkhead TR, Møller AP, Sutherland WJ (1993) Why do females make it so difficult for males to fertilize their eggs? J Theor Biol 161:51-60

Brown MJF, Schmid-Hempel P (2003) The evolution of female multiple mating in social Hymenoptera. Evolution 57:2067-2081

Burness G, Casselman SJ, Schulte-Hostedde AI, Moyes CD, Montgomerie R (2004) Sperm swimming speed and energetics vary with sperm competition risk in bluegill (Lepomis macrochirus). Behav Ecol Sociobiol 56:65-70

Clement TS, Grens KE, Fernald RD (2005) Female affiliative preference depends on reproductive state in the African cichlid fish, Astatotilapia burtoni. Behav Ecol 16:83-88

Colegrave N, Kotiaho JS, Tomkins JL (2002) Mate choice or polyandry: reconciling genetic compatibility and good genes sexual selection. Evol Ecol Res 4:911-917

Collins EJ, McNamara JM, Ramsey DM (2006) Learning rules for optimal selection in a varying environment: mate choice revisited. Behav Ecol 17:799-809

Colombo L, Marconato A, Colombo Belvedere P, Friso C (1980) Endocrinology of teleost reproduction: a testicular steroid pheromone in the black goby, Gobius jozo L. Boll Zool 47:355-364

Coulter GW (1991) Lake Tanganyika and its life. Oxford University Press, Oxford

Dombrovsky Y, Perrin N (1994) On adaptive search and optimal stopping in sequential mate choice. Am Nat 144:355-361

Eberhard WG (1996) Female Control: Sexual Selection by Cryptic Female Choice. Princeton University Press, Princeton

Elofsson H, McAllister BG, Kime DE, Mayer I, Borg B (2003) Long lasting stickleback sperm: is ovarian fluid a key to success in fresh water? J Fish Biol 63:240-253

Evans JP, Magurran AE (2000) Multiple benefits of multiple mating in guppies. Proc Natl Acad Sci U SA 97:10074-10076

Fisher DO, Double MC, Blomberg SP, Jennions MD, Cockburn A (2006) Post-mating sexual selection increases lifetime fitness of polyandrous females in the wild. Nature 444:89-92

Fox CW, Rauter CM (2003) Bet-hedging and the evolution of 527 multiple mating. Evol Ecol Res 5:273-286

Gomendio M, Roldan ERS (1991) Sperm competition influences sperm size in mammals. Proc Royal Soc Lond B 243:181-185

Goodwin NB, Balshine-Earn S, Reynolds JD (1998) Evolutionary transitions in parental care in cichlid fish. Proc Royal Soc Lond B 265:2265-2272

Gowaty PA (1994) Architects of sperm competition. Trends Ecol Evol 9:160-162

Grier HJ (1981) Cellular organization of the testes and spermatogenesis in fishes. Am Zool 21:345-357

Grier HJ, Fishelson L (1995) Colloidal sperm-packaging in mouthbrooding tilapiine fishes. Copeia 4:966-970

Griffith SC, Owens IPF, Thuman KA (2002) Extra pair paternity in birds: a review of interspecific variation and adaptive function. Mol Ecol 11:2195-2212

Haesler MP (2007) Sequential mate choice decisions and sperm competition in mouthbrooding cichlids. PhD thesis, University of Bern, Switzerland

Harvey PH, May RM (1989) Out for the sperm count. Nature 337:508-509
Hert E (1989) The function of egg-spots in an African mouthbrooding cichlid fish. Anim Behav 37:726-732

Höglund J, Alatalo R (1995) Leks. Princeton University Press, Princeton

Hosken DJ, Blanckenhorn WU (1999) Female multiple mating, inbreeding avoidance, and fitness: it is not only the magnitude of costs and benefits that counts. Behav Ecol 10:462-464

Hosken DJ, Garner TWJ, Tregenza T, Wedell N, Ward PI (2003) Superior sperm competitors sire higher-quality young. Proc Royal Soc Lond B 270:1933-1938

Immler S, Mazzoldi C, Rasotto MB (2004) From sneaker to parental male: change of reproductive traits in the black goby, Gobius niger (Teleostei, Gobiidae). J Exp Zool 301A:177-185

Ivy TM, Sakaluk SK (2005) Polyandry promotes enhanced offspring survival in decorated crickets. Evolution 59:152-159

Jennions MD, Petrie M (2000) Why do females mate multiply? A review of the genetic benefits. Biol Rev 75:21-64

Keller L, Reeve HK (1995) Why do females mate with multiple males? The sexually selected sperm hypothesis. Adv Study Behav 24:291-315

Kellogg KA, Markert JA, Stauffer JR Jr, Kocher TD (1995) Microsatellite variation demonstrates multiple paternity in lekking fishes from lake Malawi, Africa. Proc Royal Soc London B 260:79-84

Kempenaers B, Verheyen GR, Van den Broeck M, Burke T, Van Broekhoven C, Dhont A (1992) Extra-pair paternity results from female preference for high quality males in the blue tit. Nature 357:494-496

Knight ME, Turner GF, Rico C, van Oppen MJH, Hewitt GM (1998) Microsatellite paternity analysis on captive Lake Malawi cichlids supports reproductive isolation by direct mate choice. Mol Ecol $7: 1605-1610$

Konings A (1988) Tanganyika Cichlids. Verduijn Cichlids, Zevenhuizen

Konior M, Radwan J, Kolodziejczyk M (2001) Polyandry increases offspring fecundity in the bulb mite. Evolution 55: $1893-1896$

Kuwamura T (1997) The evolution of parental care and mating systems among Tanganyikan cichlids. In: Kawanabe H, Hori M, Nagoshi M (eds) Fish Communities in Lake Tanganyika. Kyoto University Press, Kyoto, pp 57-86

Le Comber S, Faulkes CG, Van Look KJW, Holt WV, Smith C (2004) Recovery of sperm activity after osmotic shock in the threespined stickleback: implications for pre-oviposition behaviour. Behaviour 141:1555-1570

Liem KF (1981) A phyletic study of the Lake Tanganyika cichlid genera Asprotilapia, Ectodus, Lestradea, Cunningtonia, Ophthalmochromis and Ophthalmotilapia. Bull Mus Comp Zool 149:191-214

Linhart O, Rodina M, Gela D, Kocour M, Vandeputte M (2005) Spermatozoal competition in common carp (Cyprinus carpio): what is the primary determinant of competition success? Reproduction 130:705-711

Locatello L, Mazzoldi C, Rasotto MB (2002) Ejaculate of sneaker males is pheromonally inconspicuous in the black goby, Gobius niger (Teleostei, Gobiidae). J Exp Zool 293:601-605

Maan ME, Seehausen O, Soderberg L, Johnson L, Ripmeester EAP, Mrosso HDJ, Taylor MI, Van Alphen JJM (2004) Intraspecific sexual selection on a speciation trait, male coloration, in the Lake Victoria cichlid Pundamilia nyererei. Proc Royal Soc London B Biol Sci 271:2445-2452

Marconato A, Rasotto MB, Mazzoldi C (1996) On the mechanism of sperm release in three gobiid fishes (Teleostei: Gobiidae). Environ Biol Fishes 46:321-327

Maynard-Smith J, Harper D (2003) Animal signals. University Press, Oxford 
McKaye KR (1991) Sexual selection and the evolution of the cichlid fishes of Lake Malawi, Africa. In: Keenleyside MHA (ed) Cichlid Fishes: behaviour, ecology and evolution. Chapman and Hall, New York, pp 241-257

Morisawa M (1994) Cell signaling mechanism for sperm motility. Zoological Science 11:647-662

Mrowka W (1987) Oral fertilization in a mouthbrooding cichlid fish. Ethology 74:293-296

Nakatsuru K, Kramer DL (1982) Is sperm cheap? Limited male fertility and female choice in the Lemon Tetra (Pisces, Characidae). Science 216:753-755

Neat FC, Balshine-Earn S (1999) A field survey of the breeding habits of Eretmodus cyanostictus, a biparental mouthbrooding cichlid in Lake Tanganyika. Environ Biol Fishes 55:333-338

Neff BD (2004) Increased performance of offspring sired by parasitic males in bluegill sunfish. Behav Ecol 15:327-331

Nordeide JT (2007) Is there more in 'gamete quality' than quality of the gametes? A review of effects of female mate choice and genetic compatibility on offspring quality. Aquac Res 38:1-16

Okuda N (1999) Female mating strategy and male brood cannibalism in a sand-dwelling cardinalfish. Anim Behav 58:273-279

Parker GA (1990a) Sperm competition games: raffles and roles. Proc Royal Soc Lond B 242:120-126

Parker GA (1990b) Sperm competition games: sneaks and extra-pair copulations. Proc Royal Soc Lond B 242:127-133

Parker A, Kornfield I (1996) Polygynandry in Pseudotropheus zebra, a cichlid fish from Lake Malawi. Environ Biol Fishes 47:345352

Pearse AGE (1985) Histochemistry. Theoretical and applied analytical technology. Churchill Livingstone, Edinburgh

Pellegrin J (1904) Contribution à l'étude anatomique, biologique et taxonomique des poissons de la famille des Cichlides. Mém Socé Zool Fr 16:41-402

Pizzari T, Birkhead TR (2002) The sexually-selected sperm hypothesis: sex-biased inheritance and sexual antagonism. Biol Rev 77:183209

Plenderleith M, van Oosterhout C, Robinson RL, Turner GF (2005) Female preference for conspecific males based on olfactory cues in a Lake Malawi cichlid fish. Biology Letters 1:411-414

Rasotto MB, Shapiro DY (1998) Morphology of gonoducts and male genital papilla, in the bluehead wrasse: implications and correlates on the control of gamete release. J Fish Biol 52:716-725

Rasotto MB, Mazzoldi C (2002) Male traits associated with alternative reproductive tactics in Gobius niger. J Fish Biol 61:173-184

Rintamäki PT, Alatalo R, Höglund J, Lundberg A (1995) Mate sampling behaviour of black grouse females. Behav Ecol Sociobiol 37:209-215

Rossiter A, Yamagashi S (1997) Intraspecific plasticity in the social system and mating behaviour of a lek-breeding cichlid fish. In: Kawanabe H, Hori M, Nagoshi M (ed) Fish communities in Lake Tanganyika, pp. 194-217

Rudolfsen G, Figenschou L, Folstad I, Nordeide JT, Soreng E (2005) Potential fitness benefits from mate selection in the Atlantic cod (Gadus morhua). J Evol Biol 18:172-179

Salzburger W, Braasch I, Meyer A (2007) Adaptive sequence evolution in a color gene involved in the formation of the characteristic egg-dummies of male haplochromine cichlid fishes. BMC Biology 5:51

Sato T, Hirose M, Taborsky M, Kimura S (2004) Size-dependent male alternative reproductive tactics in the shell-brooding cichlid fish Lamprologus callipterus in Lake Tanganyika. Ethology 110:49-62

Scaggiante M, Mazzoldi C, Petersen CW, Rasotto MB (1999) Sperm competition and mode of fertilization in the grass goby Zosterisessor ophiocephalus (Teleostei: Gobiidae). J Exp Zool 283:81-90
Schaedelin FC, Taborsky M (2006) Mating craters of Cyathopharynx furcifer (Cichlidae) are individually specific, extended phenotypes. Anim Behav 72:753-761

Schulte-Hostedde AI, Burness G (2005) Fertilization dynamics of sperm from different male mating tactics in bluegill (Lepomis macrochirus). Can J Zool 83:1638-1642

Shapiro DY, Marconato A, Yoshikawa T (1994) Sperm economy in a coral-reef fish, Thalassemia bifasciatum. Ecology 75:1334-1344

Sheldon BC (1994) Male phenotype, fertility, and the persuit of extrapair copulations by female birds. Proc Roy Soc Lond B 257:25-30

Simmons LW (1992) Quantification of role reversal in relative parental investment in a bush cricket. Nature 358:61-63

Simmons LW (2001) The evolution of polyandry: an examination of the genetic incompatibility and good-sperm hypotheses. J Evol Biol 14:585-594

Simmons LW (2003) The evolution of polyandry: patterns of genotypic variation in female mating frequency, male fertilization success and a test of sexy-sperm hypothesis. J Evol Biol 16:624 634

Simmons LW (2005) The evolution of polyandry: sperm competition, sperm selection, and offspring viability. Annu Rev Ecol Evol Systemat 36:125-146

Simmons LW, Kotiaho JS (2007) Quantitative genetic correlation between trait and preference supports a sexually selected sperm process. Proc Natl Acad Sci U S A 104:16604-16608

Stockley P (1999) Sperm selection and genetic incompatibility: does relatedness of mates affect male success in sperm competition? Proc Royal Soc Lond B Biol Sci 266:1663-1669

Stockley P (2003) Female multiple mating behaviour, early reproductive failure and litter size variation in mammals. Proc Royal Soc Lond B 270:271-278

Stockley P, Gage MJG, Parker GA, Møller AP (1996) Female reproductive biology and the evolution of ejaculate characteristics in fish. Proc Royal Soc Lond B 263:451-458

Taborsky M (1994) Sneakers, satellites and helpers: parasitic and cooperative behaviour in fish reproduction. Advanced Studies of Behavior 23:1-100

Taborsky M (1998) Sperm competition in fish: 'bourgeois' males and parasitic spawning. Trends Ecol Evol 13:222-227

Taborsky M (2008) Alternative reproductive tactics in fish. In: Oliveira RF, Taborsky M, Brockmann HJ (eds) Alternative reproductive tactics - an integrative approach. Cambridge University Press, Cambridge, pp 251-299

Takai H, Morisawa M (1995) Change in intracellular Kp concentration caused by external osmolality change regulates sperm motility of marine and fresh water teleosts. J Cell Sci 108:1175-1181

Torres-Vila LM, Rodriguez-Molina MC, McMinn M, RodriguezMolinac A (2005) Larval food source promotes cyclic seasonal variation in polyandry in the moth Lobesia botrana. Behav Ecol $16: 114-122$

Tregenza T, Wedell N (2000) Genetic compatibility, mate choice and patterns of parentage: invited review. Mol Ecol 9:1013-1027

Trippel EA, Morgan MJ (1994) Sperm longevity in pelagic spawning cod (Gadus morhua). Copeia 1994:1025-1029

Urbach D, Folstad I, Rudolfsen G (2005) Effects of ovarian fluid on sperm velocity in Arctic charr (Salvelinus alpinus). Behav Ecol Sociobiol 57:438-444

Vladic TV, Järvi T (2001) Sperm quality in the alternative reproductive tactics of Atlantic salmon: the importance of the loaded raffle mechanism. Royal Soc Lond B 268:2375-2381

Warner RR (1997) Sperm allocation in coral reef fishes. BioScience 47:561-564

Warner RR, Shapiro DY, Marconato A, Petersen CW (1995) Sexual conflict - males with highest mating success convey the lowest 
fertilization benefits to females. Proc Royal Soc Lond B 262:135-139

Wedell N, Gage MJG, Parker GA (2002) Sperm competition, male prudence and sperm-limited females. Trends Ecol Evol 17:313-320

Wickler W (1962a) 'Egg-dummies' as natural releasers in mouthbreeding cichlids. Nature 194:1092-1093

Wickler W (1962b) Ei-Attrappen und Maulbrüten bei afrikanischen Cichliden. Z Tierpsychol 19:126-164

Wiklund C, Karlsson B, Leimar O (2001) Sexual conflict and cooperation in butterfly reproduction: a comparative study of polyandry and female fitness. Proc Royal Soc Lond B 268:1661-1667

Wirtz P (1997) Sperm selection by females. Trends Ecol Evol 12:172-173
Yasui Y (1997) A "good-sperm" model can explain the evolution of costly multiple mating by females. Am Nat 149:573-584

Yasui Y (1998) The 'genetic benefits' of female multiple mating reconsidered. Trends Ecol Evol 13:1998

Yasui Y (2001) Special submission as a genetic bet-hedging strategy when mate choice criteria are unreliable. Ecol Res 16:605-516

Zeh JA, Zeh DW (1996) The evolution of polyandry I. Postcopulatory defence against genetic incompatibility. Proc Royal Soc Lond B 263:1711-1717

Zeh JA, Zeh DW (2003) Toward a new sexual selection paradigm: Polyandry, conflict and incompatibility (Invited article). Ethology 109:929-950 